\title{
IMPROVEMENT OF THE ALGORITHM FOR DIAGNOSTICS OF POSTCHOLECYSTECTOMY SYNDROME TAKING INTO ACCOUNT FUNCTIONAL AND ORGANIC CHANGES IN THE AREA OF THE LARGE DUODENAL NIPPLE
}

\author{
Nikolai Veligotsky \\ Department of Thoracoabdominal Surgery ${ }^{1}$ \\ Karyna Aleksanian $\bowtie$ \\ Department of Thoracoabdominal Surgery ${ }^{1}$ \\ karina.aleksanyan91@gmail.com \\ Sergei Arutyunov \\ Department of Thoracoabdominal Surgery ${ }^{1}$ \\ Alexandr Gorbulitch \\ Department of Thoracoabdominal Surgery ${ }^{I}$ \\ ${ }^{1}$ Kharkiv Medical Academy of Postgraduate Education \\ Amosova str., 58, Kharkiv, Ukraine, 61176
}

$\triangle$ Corresponding author

\begin{abstract}
The aim. Improving the algorithm for diagnosing patients with postcholecystectomy syndrome (PCS), taking into account functional and organic changes in the major duodenal papilla (MDP).

Materials and methods. 208 patients with PCS were examined. Laparoscopic cholecystectomy (CE) was performed in 172 patients in history, open CE was performed in 36 patients. 47 patients had obstructive jaundice, 84 had signs of biliary hypertension without an increase in bilirubin, 77 had no signs of biliary hypertension and an increase in bilirubin.

The following instrumental research methods were used: abdominal organs ultrasound examination (AO USE), duodenoscopy, endoscopic retrograde cholangiopancreatography (ERCP), computed tomography (CT). In the main group, to study the morphofunctional changes in MDP, duodenoscopy with parietal impedancemetry, ultrasound of the hepatobiliary zone with a choleretic load were used.

Results. In the main group, 34 patients underwent ultrasound of the hepatobiliary zone and Vater's nipple area with a choleretic breakfast according to Boyden according to the method of Grigoriev P.Ya. in our modification, 21 patients had an expansion of the choledochus by $2 \mathrm{~mm}$. At the same time, taking meverin led to a decrease in the diameter of the choledochus, which indicated functional changes in the MDP. In 13 patients, the expansion of the choledochus, observed when taking a choleretic breakfast, persisted with the use of antispasmodics, which indicated the presence of an organic pathology of MDP. Duodenoscopy with impedancemetry was performed in 41 patients: 20 patients had $760-820 \mathrm{Ohm}$, which indicated the presence of functional changes, 12 patients had inflammatory changes in the MDP and 703-760 Ohm were detected, 9 patients with cicatricial fibrous changes had indicators impedance measurement 640-703 Ohm. The use of ultrasound with a choleretic breakfast and duodenoscopy with parietal impedancemetry in patients of the main group made it possible to identify functional and organic (inflammatory, fibrous) changes in the MDP, which made it possible to develop a therapeutic algorithm using both conservative therapy and the use of various options for transpapillary endoscopic interventions.

Conclusions. Conducting an in-depth diagnosis of morpho-functional changes in MDP using parietal impedancemetry of MDP and ultrasound of the hepatobiliary zone with choleretic load allows us to identify both functional and morphological changes in MDP, which makes it possible to develop a therapeutic algorithm using drug therapy and transpapillary endoscopic techniques.

Keywords: postcholecystectomy syndrome, impedancemetry, functional and organic changes in the major duodenal papilla.
\end{abstract}

DOI: $10.21303 / 2504-5679.2022 .002234$

\section{Introduction}

Postcholecystectomy syndrome (PCS) is a symptom complex that contains functional and organic disorders of the major duodenal papilla (MDP) [1, 2]. The most co mmon causes of PCS, both after cholecystectomy (CE) performed by the «open» method, and after laparoscopic CE, are: 
stones forgotten or moved during intervention in the choledochus from the gallbladder or cystic duct [3], recurrent choledocholithiasis (mainly after preliminary endoscopic manipulations with stone extraction attempts) [4, 5], MDP restenosis after endoscopic papillosphincterotomy (EPST) [6], blind pouch syndrome, long vesical stump syndrome, biliary fistula, tubular stenosis of the distal choledochus due to chronic indurative pancreatitis, reflux cholangitis due to total EPST and wide choledochoduodenoanastomosis, electrical injury of the biliary tract [7, 8]. An important role may be played by the lack of proper compliance in patients in the postoperative period regarding preventive measures aimed at preventing PCS [9].

Examination of patients who have undergone CE is relevant, both for the purpose of choosing further treatment tactics depending on the identified pathology, and for the purpose of developing measures that are aimed at preventing PCS [10,11].

The aim of the research: improvement of the algorithm for diagnosing patients with PCS, taking into account functional and organic changes in the MDP area.

\section{Materials and methods}

The study was conducted on the basis of the KCC «City Clinical Hospital for Emergency and Emergency Medical Care named after prof. A. I. Meshchaninov» from 2018 to 2021.

$208(100 \%)$ patients with PCS were examined: in the main group - 94 (45.2\%) patients, in the comparison group - 114 (54.8\%) patients. The comparison group consisted of patients who were hospitalized from 2018 to 2020 in surgical departments and who underwent standard examinations - laboratory, ultrasound examination of the abdominal organs, endoscopic fibrogastroduodenoscopy, endoscopic retrograde cholangiopancreatography, multidetector computed tomography or magnetic resonance imaging. The main group included patients who were hospitalized in surgical departments from 2020 to 2021, who, in addition to standard examination methods, used additional methods - parietal impedancemetry MDP and ultrasound of the hepatobiliary zone with choleretic load in order to assess morphofunctional changes in MDP.

Laparoscopic CE was performed in $172(82.7 \%)$ patients, and open CE was performed in $36(17.3 \%)$ patients. 47 (22.6\%) patients had obstructive jaundice, 84 (40.4\%) had signs of biliary hypertension without an increase in bilirubin, 77 (37\%) had no signs of biliary hypertension and an increase in bilirubin.

An informed agreement was obtained from all study participants. The work was carried out in accordance with the Code of Ethics of the World Medical Association (Declaration of Helsinki). The Committee of the Commission of the Kharkiv Medical Academy of Postgraduate Education on Bioethics approved and approved Protocol No. 3 dated 10/12/2021.

The following instrumental research methods were used: abdominal organs ultrasound examination (AO USE), duodenoscopy, endoscopic retrograde cholangiopancreatography (ERCP), computed tomography (CT). In the main group, to study the morphological and functional changes in MDP, duodenoscopy with parietal impedancemetry, ultrasound with a choleretic breakfast were used.

To perform impedancemetry, a device for ph-impedance monitoring $(\mathrm{pH}-\mathrm{Z})$ was used, to which a probe with 6 sensors was connected, of which 4 impedance sensors and 2 ph sensors (Fig. 1). After cannulation of the MDP, the impedance spectrum was determined at frequencies from 1 to $10 \mathrm{kHz}$.

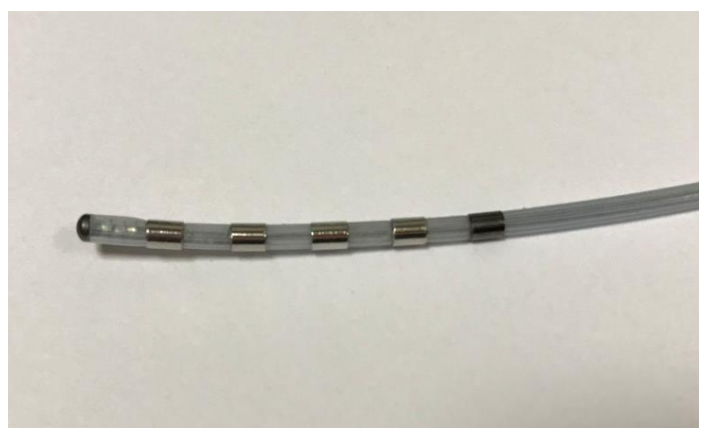

Fig. 1. Ph- and impedance probe sensors for ph-impedance monitoring MDP 
Ultrasound of the hepatobiliary zone and the region of Vater's nipple with a choleretic breakfast according to Boyden according to the method of Grigoriev P.Ya. in our modification (author's certificate No. 106257 «Method for diagnosing morphological changes in the sphincter of Oddi») was carried out in patients in order to assess the function of the sphincter of Oddi (SO) and in the absence of data for organic obstruction of the MDP zone at previous stages of examination. First, a thorough study of the hepatobiliary zone, including the MDP area, was performed, measuring the initial width of the CBD. After a food load in the amount of two raw chicken yolks, the measurement of the common bile duct was carried out every 15 minutes for 1 hour. Its expansion by $2 \mathrm{~mm}$ or more, in comparison with the initial one, made it possible to suspect incomplete obstruction of the choledochus, the cause of which could be SO dysfunction or organic changes in the MDP area. A decrease in the width of the common bile duct while taking an antispasmodic (meverin) indicated functional disorders of the SO (spasm).

Statistical processing was performed on a personal computer using the standard Microsoft Office Excel 2016 application package and the Statistica 6.0 program. To determine the statistical significance of differences between the study groups, a non-parametric $\chi^{2}$ method (Pearson's test) was used.

\section{Results}

In the main group, 34 (36.2\%) patients underwent ultrasound of the hepatobiliary zone and Vater's nipple area with a choleretic breakfast according to Boyden according to the method of Grigoriev P. Ya. in our modification. When performing this study, 21 (22.3\%) patients showed an expansion of the choledochus by $2 \mathrm{~mm}$. At the same time, taking meverin led to a decrease in the diameter of the choledochus, which indicated functional changes in MDP. In 13 (13.8\%) patients, the expansion of the choledochus, observed when taking a choleretic breakfast, persisted with the use of antispasmodics, which indicated the presence of an organic pathology of MDP.

Duodenoscopy with impedancemetry (Fig. 2) was performed in 41 (43.6\%) patients: in $20(21.3 \%)$ patients, indicators of $760-820 \mathrm{Ohm}$ were noted, which indicated the presence of functional changes, in 12 (12.8\%) Inflammatory changes in the MDP were noted in patients and indicators of 703-760 Ohm were detected, in 9 (9.6\%) patients with cicatricial fibrous changes, impedancemetry values of 640-703 Ohm were noted.

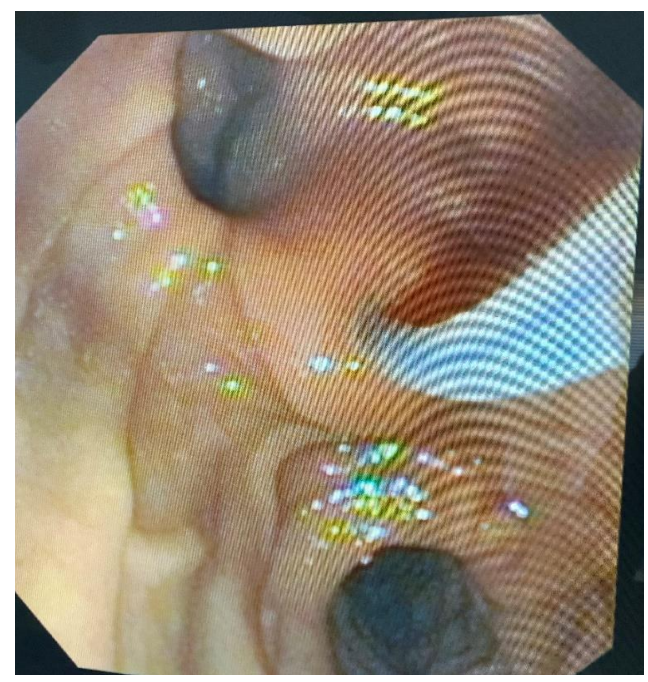

Fig. 2. Cannulation of the MDP with a ph-impedance probe during duodenoscopy

When comparing the data obtained by ultrasound with a choleretic breakfast and the data of parietal impedancemetry, a strong direct correlation was revealed (Table 1).

That is, there is a significant relationship between the frequency of detection of choledocholithiasis and the type of changes in the MDP that are detected by impedancemetry. 
The use of ultrasound with a choleretic breakfast and duodenoscopy with parietal impedancemetry in patients of the main group made it possible to identify functional and organic (inflammatory, fibrous) changes in the MDP, which made it possible to develop a therapeutic algorithm using both conservative therapy and the use of various options for transpapillary endoscopic interventions.

Table 1

Morphofunctional changes in the MDP area

\begin{tabular}{clcccc}
\hline \multirow{2}{*}{ The nature of the changes in the MDP } & \multicolumn{2}{c}{ With choledocholiasis } & \multicolumn{2}{c}{ Without choledocholiasis } & \multirow{2}{*}{ Total } \\
\cline { 2 - 4 } & $\mathbf{N}$ & $\mathbf{\%}$ & $\mathbf{N}$ & $\mathbf{\%}$ & $53 \%$ \\
\hline MDP functional changes & 14 & $47 \%$ & 30 & $13 \%$ & 24 \\
Inflammatory changes (stenosing) of MDP & 21 & $88 \%$ & 6 & $23 \%$ & 26
\end{tabular}

Note: differences between groups are statistically significant $X_{\text {calc }}^{2}=11.5, X_{\text {crit }}^{2}=9.2, p<0.01$

In $16(17 \%)$ patients with functional changes in MDP and absence of choledocholithiasis, conservative therapy was applied with the use of duspatalin, ursodeoxycholic acid preparations.

In $14(14.9 \%)$ patients with functional changes with choledocholithiasis (Fig. 3, 4), the following transpapillary endoscopic interventions were used: in $6(6.4 \%)$ patients with choledocholithiasis (calculi size 3-7 mm), partial endoscopic papillosphincterotomy, choledocholithoextraction (Fig. 5), all 8 (8.5\%) patients with biliary sludge and microcholedocholithiasis underwent balloon dilatation and sanitation of hepaticocholedochus with good immediate and long-term results. In this regard, we note that the use of balloon dilatation according to indications in the treatment of microcholedocholithiasis and biliary sludge in patients with functional changes in MDP is the most optimal surgical intervention.

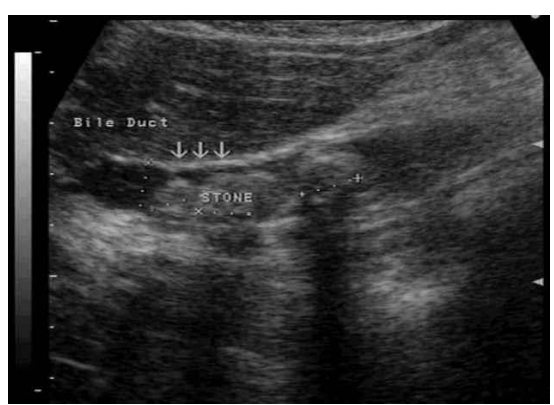

Fig. 3. Ultrasonography. Choledocholithiasis

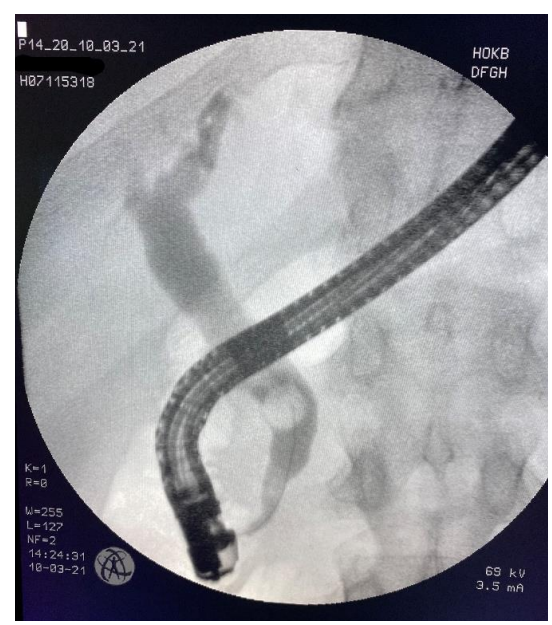

Fig. 4. ERCP. Choledocholithiasis 


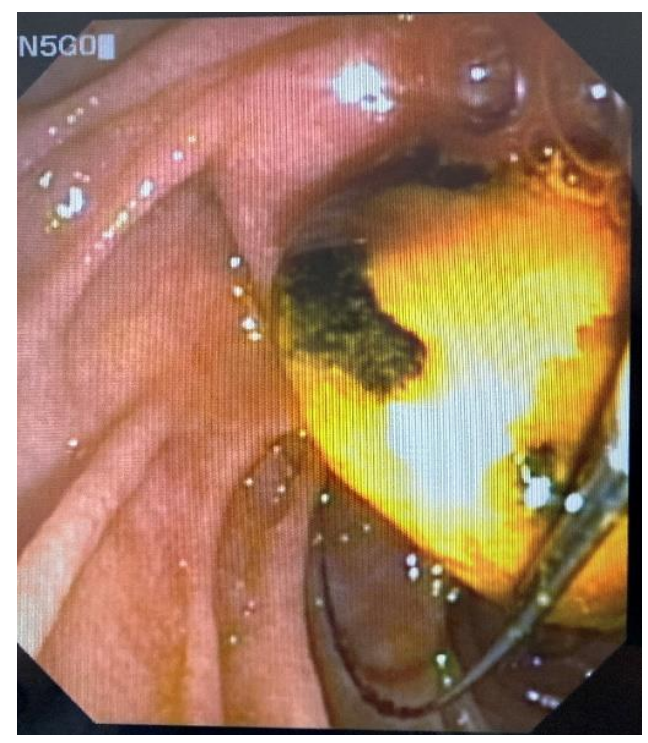

Fig. 5. Endoscopic choledocholithoextraction

In $24(25.5 \%)$ patients, inflammatory changes in the MDP (stenosing processes) were detected. In 3 (3.2\%) patients with MDP inflammatory processes and the absence of choledocholithiasis, conservative therapy was applied using duspatalin, ursodeoxycholic acid preparations, in $21(22.3 \%)$ patients with MDP inflammatory stenosing processes and choledocholithiasis, transpapillary endoscopic interventions were used: in $12(12.8 \%)$ patients with choledocholithiasis (calculi size 3-7 mm) underwent partial papillosphykterotomy, choledocholithoextraction, $9(9.6 \%)$ patients with large calculi $(8-15 \mathrm{~mm})$ underwent subtotal papillosphincterotomy.

In 26 (27.7 \%) patients, cicatricial-fibrotic changes in MDP were detected, while 20 (21.3\%) patients had choledocholithiasis. This group underwent transpapillary endoscopic interventions. 13 (13.8\%) patients underwent partial EPST, 8 (8.5\%) patients underwent subtotal EPST, and 5 $(5.3 \%)$ patients underwent total EPST.

\section{Discussion}

PCS is a condition that quite often complicates $(25-40 \%)$ the postoperative course of cholelithiasis $[12,13]$. The presence of symptoms of the disease indicates a deterioration in the quality of life of patients, however, with the diagnostic confirmation of PCS, it is not always possible to identify morphological or functional changes [14]. The use of ultrasound of the hepatobiliary region and the zone of Vater's nipple with a choleretic breakfast according to Boyden according to the method of P.Ya. Grigoriev in our modification made it possible in the study group in $22.3 \%$ of patients to reveal the expansion of the choledochus by $2 \mathrm{~mm}$, the width of which decreased after taking meverin, which was regarded as functional changes in MDP. In $13.8 \%$, the expansion of the choledochus, after taking breakfast with a choleretic load, persisted against the background of the use of meverin, which indicated an organic pathology in the MDP area. The method of parietal impedancemetry MDP, during duodenoscopy, in the study group in $21.3 \%$ of patients showed resistance indicators of $760-820 \mathrm{Ohm}$, which indicated functional changes in this area [15]. In $12.8 \%$ of patients, resistance values of 703-760 Ohm were detected in the presence of visual signs of MDP inflammation (edema, hyperemia), and in $9.6 \%$ of patients with visual cicatricial fibrous changes, resistance indicators were $640-703 \mathrm{Ohm}$. The methods used can be used for the purpose of differential diagnosis between functional and organic pathology of MDP [16, 17].

Study limitations. Ultrasound examination of the hepatobiliary region with choleretic load is a non-invasive method for the differential diagnosis of organic and functional pathology in the MDP region, however, it has its limitations, namely, proven choledocholithiasis, previously performed by EPST, which may affect the function of the sphincter of Oddi [18, 19]. MDP 
impedancemetry is performed during duodenoscopy, and cannulation of the MDP may be difficult in the presence of MDP diverticula, wedged calculi in Vater's nipple, etc. [20].

Prospects for further research. Despite the possible limitations of these research methods, they remain promising for the differential diagnosis of morphological and functional changes in the MDP area, since the method of impedancemetry can be used routinely during duodenoscopy, and the method of ultrasound with a choleretic load is non-invasive for diagnosing disorders of the sphincter of Oddi in patients with PCS.

\section{Conclusions}

Conducting an in-depth diagnosis of morphofunctional changes in MDP makes it possible to identify both functional and morphological changes in MDP, which makes it possible to develop a therapeutic algorithm using drug therapy and transpapillary endoscopic techniques, including balloon dilatation, endosanation of the biliary tract, endoscopic papillosphincterotomy, endoscopic stenting of the common bile duct and others.

When detecting inflammatory and cicatricial changes in the MDP, the probability of detecting choledocholithiasis is $88 \%$ and $77 \%$, which requires careful identification of stones using other research methods.

Performing parietal impedancemetry and ultrasound with a choleretic breakfast in patients with PCS makes it possible to differentiate the diagnosis of morphofunctional changes in MDP and choose the optimal treatment method.

\section{Conflict of interests}

The authors declare there is no conflict of interests.

\section{Financing}

The study was conducted without financial support.

\section{References}

[1] Shirah, B. H., Shirah, H. A., Zafar, S. H., Albeladi, K. B. (2018). Clinical patterns of postcholecystectomy syndrome. Annals of Hepato-Biliary-Pancreatic Surgery, 22 (1), 52-57. doi: http://doi.org/10.14701/ahbps.2018.22.1.52

[2] Kim, H., Han, I. W., Heo, J. S., Oh, M. G., Lim, C. Y., Choi, Y. S., Lee, S. E. (2018). Postcholecystectomy syndrome: symptom clusters after laparoscopic cholecystectomy. Annals of Surgical Treatment and Research, 95 (3), 135-140. doi: http:// doi.org/10.4174/astr.2018.95.3.135

[3] Veligotsky, N. N., Lazutkina, E. A., Arutyunov, S. E., Menkus, B. V., Taran, Y. Y., Aleksanian, K. A. (2018). Postcholecystectomy syndrome from the position of surgeon and gastroenterologist. Ukrainian Journal of Surgery, 2 (37), 16-21. doi: http:// doi.org/10.22141/1997-2938.2.37.2018.147842

[4] Watanabe, M., Okuwaki, K., Kida, M., Imaizumi, H., Yamauchi, H., Kaneko, T. et. al. (2019). Transpapillary Biliary Cannulation is Difficult in Cases with Large Oral Protrusion of the Duodenal Papilla. Digestive Diseases and Sciences, 64 (8), 2291-2299. doi: http://doi.org/10.1007/s10620-019-05510-z

[5] Schofer, J. M. (2010). Biliary Causes of Postcholecystectomy Syndrome. The Journal of Emergency Medicine, 39 (4), $406-410$. doi: http://doi.org/10.1016/j.jemermed.2007.11.090

[6] Leontev, A. S., Korotkevich, A. G., Repnikova, R. V., Merzlyakov, M. V., Shestak, I. S. (2015). Endoscopic diagnosis and parietal impedancometry in the assessment of changes in the mucosa of the duodenumin patients with suspicion on postcholecystectomy syndrome. Experimental and clinical gastroenterology, 116 (4), 34-37.

[7] Phillips, M. R., Joseph, M., Dellon, E. S., Grimm, I., Farrell, T. M., Rupp, C. C. (2014). Surgical and Endoscopic Management of Remnant Cystic Duct Lithiasis After Cholecystectomy - a Case Series. Journal of Gastrointestinal Surgery, 18 (7), 1278-1283. doi: http://doi.org/10.1007/s11605-014-2530-4

[8] Galperin, E. I., Vetshev, P. S. (2009). Rukovodstvo po chirurgii schelchnich putey. Moscow: Publishing house Vidar-M, 568.

[9] Sazhyn, V. P., Fedorov, A. V., Sazhyn, A. V. (2010). Endoskopicheskaya Chirurgiya. Moscow: GEOTAR Media, $214-255$.

[10] Dasari, B. V., Tan, C. J., Gurusamy, K. S., Martin, D. J., Kirk, G., McKie, L. et. al. (2013). Surgical versus endoscopic treatment of bile duct stones. Cochrane Database of Systematic Reviews. doi: http://doi.org/10.1002/14651858.cd003327.pub4

[11] ElGeidie, A. A. (2014). Single-session minimally invasive management of common bile duct stones. World Journal of Gastroenterology, 20 (41), 15144-15152. doi: http://doi.org/10.3748/wjg.v20.i41.15144 
[12] Giljaca, V., Gurusamy, K. S., Takwoingi, Y., Higgie, D., Poropat, G., Štimac, D., Davidson, B. R. (2015). Endoscopic ultrasound versus magnetic resonance cholangiopancreatography for common bile duct stones. Cochrane Database of Systematic Reviews. doi: http://doi.org/10.1002/14651858.cd011549

[13] Ledro-Cano, D. (2007). Suspected choledocholithiasis: endoscopic ultrasound or magnetic resonance cholangio-pancreatography? A systematic review. European Journal of Gastroenterology \& Hepatology, 19 (11), 1007-1011. doi: http://doi.org/ 10.1097/meg.0b013e328133f30b

[14] Kenny, R., Richardson, J., McGlone, E. R., Reddy, M., Khan, O. A. (2014). Laparoscopic common bile duct exploration versus pre or post-operative ERCP for common bile duct stones in patients undergoing cholecystectomy: Is there any difference? International Journal of Surgery, 12 (9), 989-993. doi: http://doi.org/10.1016/j.ijsu.2014.06.013

[15] Lu, J., Cheng, Y., Xiong, X.-Z., Lin, Y.-X., Wu, S.-J., Cheng, N.-S. (2012). Two-stage vs single-stage management for concomitant gallstones and common bile duct stones. World Journal of Gastroenterology, 18 (24), 3156. doi: http://doi.org/10.3748/ wjg.v18.i24.3156

[16] Wong, H.-P., Chiu, Y.-L., Shiu, B.-H., Ho, L.-C. (2011). Preoperative MRCP to detect choledocholithiasis in acute calculous cholecystitis. Journal of Hepato-Biliary-Pancreatic Sciences, 19 (4), 458-464. doi: http://doi.org/10.1007/s00534-011-0456-8

[17] Agafonova N.A. (2015). Postcholecystectomy syndrome. Moscow: Prima Print, 68 (in Russ.).

[18] Shalymov, A. A., Shalymov, S. A., Nychytajlo, M. E., Domanskyj, B. V. (1993). Chirurgia pecheni i shelchivuvodaychich putey. Kyiv: Health Protection, 512.

[19] Mcnally, M. A., Locke, G. R., Zinsmeister, A. R., Schleck, C. D., Peterson, J., Talley, N. J. (2008). Biliary events and an increased risk of new onset irritable bowel syndrome: a population-based cohort study. Alimentary Pharmacology \& Therapeutics, 28 (3), 334-343. doi: http://doi.org/10.1111/j.1365-2036.2008.03715.x

[20] Lagergren, J., Ye, W., Ekbom, A. (2001). Intestinal cancer after cholecystectomy: Is bile involved in carcinogenesis? Gastroenterology, 121 (3), 542-547. doi: http://doi.org/10.1053/gast.2001.27083

Received date 25.12.2021

(C) The Author(s) 2022

Accepted date 24.01.2022

This is an open access article

Published date 31.01.2022 under the Creative Commons CC BY license

How to cite: Veligotsky, N., Aleksanian, K., Arutyunov, S., Gorbulitch, A. (2022). Improvement of the algorithm for diagnostics of postcholecystectomy syndrome taking into account functional and organic changes in the area of the large duodenal nipple. EUREKA: Health Sciences, 1, 30-36. doi: http://doi.org/10.21303/2504-5679.2022.002234 